\title{
Inhalt des fünf und zwanzigsten Bandes.
}

\author{
E r s t e s H e f t.
}

1. Übersicht der Geschichte der Baukunst, mit Rücksicht aul die allgemeine Culturgeschichte. Von Herrn Regierungs - und Baurath C. A. Rosenthal zu Magdeburg. (Fortselzung der Abhandlung No. 2. in 1ten, No.6. im 2ten, No. 8. im 3ten Hefte 13ten, No. 1. im 1ten, No. 7. im 2ten, No. 8. im 3ten, No. 12. im 4len Hefte 14ten, No. 1. im 1ten, No. 9. im 2len, No. 11. im 3ten, No. 15. im 4ten Hefte 15ten, No. 10. im 3ten Hefte 16ten, No. 3. im 1ten, No. 5. im 2ten, No. 10. im 3ten Hefte 17ten, No. 4. im 2ten Hefte 18ten, No. 2. im 1ten Hefte 20ten und No.9. im 2ten Hefte 22ten Bandes.) . . Seite 1

2. Von den Vicatschen Vervollkommnungen des Mörtels. . . . . . . . - 33

3. Auswahl von Abhandlungen berühmter niederländischer Wasserbaukundiger über die Wasserbaue, welche in Holland an den Hauptströmen zum Schutze gegen Verwüstung nöthig sein werden. Aus dem Holländischen übersetzt und mit einer' Einleitung und Anmerkungen begleitet von Herrn Dr. Keinhold, Königl. Hannöverschem Wasserbau - Inspector; so wie mit einigen Anmerkungen des Herausgebers dieses Journals. (Fortsetzung der Abhandlung No. 4. im 2ten und No. 11. in 4ten Hefte 24ten Bandes.) . . . . . .

4. Ein sicheres, verhältnifsmäfsig wenig kostbares und auch auf schon vorhandene Eisenbahnen anwendbares Millel, zu verhüten, dafs die Wagenräder die Schienen verlassen. Voun Herausgeber. (Vorgelesen in der Königlichen Akademie der Wissenschaften zu Berlin in deren Gesammtsitzung vom 25ten Februar 1847. . . . . . . . . . . . . . . - 83

$$
Z \text { w e i t e s H e f t. }
$$

5. Des Grafen v. Pambour ,Theorie der Dampfmaschinen." Nach der zweiten Auflage dieses Werks von 1844; möglichst kurz; und mit einigen Anmerkungen des Herausgebers dieses Journals. (Fortselzung der Abhandlung No. 8. im 3ten, No. 12. im 4ten Hefte 23ten, No. 3. im 1ten, No. 5. im 2ten und No. 9. in 4ten Hefte 24ten Bandes.). . . . . . . . .

6. Versuch einer Theorie der Contraction der Bewegung des Wassers beim Ausflufs aus öffnungen in dünnen ebenen Wänden, bei unveränderlichem Niveau im Behälter; mit besonderer Rücksicht auf practische Anwendungen. Von Herrn J. Bayer, Königlich-Preufsischem Obristlieutenant im grofsen Generalstabe.

7. Auswahl von Abhandlungen berühmter niederländischer Wasserbaukundiger über die Wasserbaue, welche in Holland an den Hauptströmen zum Schutze gegen Verwüstung nöthig sein werden. Aus dem Holländischen übersetzt und mit einer Einleitung und Anmerkungen begleitet von Herrn Dr. Reinhold, Königl. Hannöverschein Wasserbau-Inspector; so wie mit einigen Anmerkungen des Herausgebers dieses Journals. (Fortsetzung der Abhandlung No. 4. im 2ten, No. 11. im 4ten Hefte 24ten und No. 3. im 1ten Hefte dieses Bandes.) 


\section{D r i t tes Heft.}

8. Über Pfahl-Ramm-Maschinen, welche durch die Spannkraft der atmosphirischen Luft und des Dampfs in Bewegung geselzt werden. Vom Herausgeber. Seite 167

9. Übersicht der Geschichte der Baukunst, mit Rücksicht auf die allgemeine Culturgeschichle. Von Herrn Regierungs- und Baurath $C_{0}$ A. Rosenthal zu Magdeburg. (Fortsetzung der Abhandlung No. 2. im 1ten, No. 6. im 2ten, No. 8. im 3ten Hefte 13ten, No. 1. im 1ten, No. 7. im 2ten, No.8. im 3ten, No. 12. im 4ten Hefte 14ten, No. 1. im 1ten, No. 9. im 2ten, No. 11. im 3ten, No. 15. im 4ten Hefte 15ten, No. 10. im 3ten Hefte 16ten, No. 3. im 1ten, No. 5. im 2ten, No. 10. im 3ten Hefte 17ten, No. 4. in 2ten Hefle 18ten, No. 2. im 1ten Hefte 20ten, No.9. im 2ten Hefle 22ten und No.1. im 1ten Hefte dieses Bandes.) . . . . . . . . . . . . . . . . . .

10. Auswahl von Abhandlungen berühmler niederländischer Wasserbaukundiger über die Wasserbaue, welche in Holland an den Hauptströmen zum Schutze gegen Verwüstung nöthig sein werden. Aus dem Holländischen überselzt und mit einer Einleitung und Anmerkungen begleitet von Herrn Dr. Rcinhold, Königl. Hannöverschem Wasserbau-Inspector; so wie mit einigen Anmerkungen des Herausgebers dieses Journals. (Fortsetzung der Abhandlung No. 4. im 2ten, No. 11. im 4ten Hefte 24ten, No. 3. im 1ten Hefte und No. 7. im zweiten Hefte dieses Bandes.)

\section{$V$ i e $r$ e s $H$ e $f$ t.}

11. Des Grafen v. P ambour "Theorie der Dampfmaschinen." Nach der zweiten Auflage dieses Werkes von 1844; möglichst kurz; und mit einigen Anmerkungen des Herausgebers dieses Journals. (Fortselzung der Abhandlung No.8. im 3ten, No. 12. im 4ten Hefte 23ten, No. 3. im 1ten, No. 5. im 2ten, No. 9. im 4ten Hefte 24ten und No. 5. im 2ten Hefte dieses Bandes.) . . .

12. Über die gewöhnlichen Ürsachen des Verfalls der mit Spitzbogen überwölbten Kirchen und über die Mittel zu ihrer Herstellung. Mit Beziehung auf wirklich geschehene Herstellungen der Art in Kurhessen: an der Stiftskirche zu Rothenburg, der Minoritenkirche zu Fritzlar und der St. Martinskirche zu

Cassel. Von dem Herrn Ober-Baumeister Engelhard zu Cassel. . . . Culturgeschichte. Von Herrn Regierungs - und Baurath C. A. Rosenthal zu Magdeburg. (Forlsetzung der Abhandlung No. 2. im 1ten, No. 6. im 2ten, No. 8. im 3ten Hefte 13ten, No. 1. im 1ten, No. 7. im 2ten, No. 8. im 3ten, No. 12. im 4ten Hefte 14ten, No. 1. im 1ten, No. 9. im 2ten, No. 11. im 3ten. No. 15. in 4ten Hefte 15ten, No. 10. im 3ten Hefte 16ten, No. 3. im 1ten, No. 5. im 2ten, No. 10. im 3ten Hefte 17ten, No. 4. im 2ten Hefte 18ten, No. 2. im 1ten Hefte 20ten, No. 9. im 2ten Hefte 22ten, No. 1. im 1ten und No. 9. im 2ten Hefle dieses Bandes.) 


\section{J o u r n a l}

f ü $\mathbf{r}$

\section{die $\mathbf{B}$ a uku n s t.}

In zwanglosen Heflion.

\section{Herausgegeben}

$\because 01$

\section{Dr. A. L. Crelle,}

Königlich-Preulsischem Geheimen-Ober-Baurathe, Mitgliede der Königlichen Akademie der Wissenschaften zu Berlin, Correspondenten der Kaiserlichen Akademie der Wissenschaften zu St. Petersburg und der Königlichen Akademieen der Wissenschaften zu Neapel und Brüssel, auswärtigem Mitgliede der Königlichen Akademie der Wissenschaften zu Stockholm, Ehrenmitgliede der Hamburger Gesellschaft zur Verbreitung der mathematischen Wissenschaften.

\section{Fünf und zwanzigster Band.}

Erstes Heft.

liteiner Figurentalel.

B e r 1 i n.

B o i r. R e i in e $r$.

1847 . 
